Fecha de recepción: mayo 2021 Fecha de aceptación: junio 2021 Versión final: julio 2021

\section{La irrupción de la pandemia en los procesos educativos. ¿ Serán estos, tiempos de pantalla y virtualidad?}

José María Aguirre ${ }^{(1)}$ y María Belén Franco ${ }^{(2)}$

Resumen: El impacto de la pandemia en la educación actual es trascendental en todos los niveles, en la educación superior es de algún modo salvable y hasta algunas veces permite que estudien quienes no hubiesen podido trasladarse; con ello en nuestras disciplinas, al momento de reconstruir nuestra idea de taller en esta situación de mediación digital, parece que perdemos y ganamos. ¿Perdemos y ganamos? O simplemente transformamos, mutamos, hibridamos y potenciamos. Hemos encontrado la posibilidad de trabajar todos juntos en un lienzo común, de buscar información o corroborar cuestiones al instante, de compartir recursos transmediales e incorporarlos en nuestras bibliotecas o backgrounds; también hemos aprendido a valorar la cotidianeidad junto a nuestros pares, lo tangible.

Palabras clave: Virtualidad - Taller - Disciplinas proyectuales - Enseñanza - Aprendizaje

[Resúmenes en inglés y portugués en la página 29]

(1) Es Arquitecto por la Universidad Católica de Córdoba (1991), Magíster en Docencia Universitaria por la Universidad Tecnológica Nacional (FRC, 2010). Profesor Titular (Dedicación Full) en Historia del Diseño Industrial I, desde 2006 y Profesor Adjunto a cargo (Carga Anexa) en Diseño Industrial III A (desde 2008) en la FAUD - UNC. Investigador categoría III de SeCyT UNC y director de proyectos de investigación. Es miembro del Consejo Asesor del CIDIC, Centro de Investigación en Diseño Industrial Córdoba, FAUD UNC y Representante por la FAUD UNC ante la Asociación Latinoamericana de Carreras de Diseño Industrial. Autor del libro DISEÑO. Aprendizaje, enseñanza y ego-axialidad. Ed. FAUD UNC, Córdoba, 2013.

(2) Es Diseñadora Industrial por la Universidad Nacional de Córdoba (2011) y Magíster en Docencia Universitaria por la Universidad Tecnológica Nacional (FRC,2017); Doctoranda en Estudios Sociales de América Latina por la Universidad Nacional de Córdoba (CEA), con su Tesis en curso en línea de Socio Antropología de la Educación. Profesora Adjunta a cargo de Estrategias de Aprendizaje (desde 2021), Profesora Adjunta de Legislación (desde 2017) y Profesora Asistente de Diseño Industrial IIB (desde 2018) en la FAUD - UNC. Investigadora de SeCyT UNC y Red Dilemas Mercosur - NEIES SPU en temas de educación. 
"Estudiar no es crear sino crearse (...), en el mejor de los casos, como creador de cultura" (Bourdieu \& Passeron, 2014, pág. 84)

\section{Virtualidad e historia}

Hoy vivimos la educación no presencial como una novedosa forma de relación interpersonal en donde media una importante diferencia espacial y temporal entre alguien que enseña, que muestra, que ofrece y otro que recibe, que aprehende. Pero no es tan así; el pasado podría convertirse en reservorio de experiencias que nos ayuden a comprender este momento, esta encrucijada histórica. Este mar de plataformas virtuales no es otra cosa que un océano de medios para los tres fines básicos de la comunicación: (i) tener información clave en reserva para, desde allí, (ii) intercambiar visiones personales de esa información $\mathrm{y}$, a partir de ese intercambio, (iii) construir nuevos conceptos con el peso y la importancia que los hagan necesarios de ser reservados ${ }^{1}$ para el futuro; y la rueda cultural sigue...

Pero esa rueda cultural comenzó a girar en el mismo momento en que el hombre, genéricamente hablando, fue capaz de construir una nueva relación conceptual digna de guardarse para la descendencia, en algún soporte con capacidad de perdurar. Llama la atención el hecho de que la raíz latina de la palabra perdurar remita a la materialidad: per (por completo) durare (solidificar, hacer sólido). La mayoría de los originales soportes históricos de información han sido siempre más que sólidos: las pinturas rupestres, las tablas de arcilla, el grabado en piedra, los frescos y murales, la alfarería, etcétera. Aunque hubieron otros, mucho menos tangibles como la tradición oral y la música, responsables también de la conservación de enormes capitales culturales antiguos y prehistóricos.

Volviendo a los soportes sólidos y al pintor rupestre, como tipo genérico, digamos que éste ha dejado huellas de una calidad artística, una claridad gráfica y un manejo de lo simbólico absolutamente envidiables todavía hoy, y su expectativa de vida no superaría seguramente los treinta o cuarenta años. Es decir que, entre la muerte de aquél y nuestro presente no ha habido otra cosa que una comunicación virtual entre ese artista y toda la posterior humanidad. Es que lo virtual tiene la virtud ${ }^{2}$ de la presencia intermediada, en este caso, la piedra pintada. Es virtual para el pintor o pintora el potencial espectador, porque el propio acto de pintar conlleva la vocación de futuro. Ni dudar que, para nosotros, es absolutamente consciente la condición de no presencial de ese autor, o autora. Aunque fueran sólo conjeturas, nos resulta lógico imaginar que fuese una mujer. Con su capacidad natural de conservar nueve meses una vida en su vientre para permitir su nacimiento a futuro, o con la experticia cultural que le permitió el desarrollo de la agricultura y la facultad de reservar alimentos para necesidades por venir, nos acomoda la idea que fueran ellas quienes crearon el arte rupestre, como modo de conservar un mensaje para la descendencia. Más allá de esta conjetura propia de un aficionado, nunca de un intelectual, lo seguro es que la autoría de esa pieza es anónima, en su más cabal expresión de anonimato. Es allí donde la virtualidad del acto comunicativo se multiplica. Sabemos muy poco del contexto que propició ese arte y sin embargo nos atrevemos a imaginar, a indagar a conjeturar sobre 
los motivos, razones, técnicas y demás variables. Nos atrevemos a aprehender lo prácticamente desconocido a partir de mínimos elementos. Eso es lo fascinante del ejercicio del pensamiento, acto que va de bruces con la hiper-exposición a la información. Aprender no es abarrotarse de datos ${ }^{3}$, sino construir una visión propia del mundo a partir de lo que escasamente nuestros sentidos puedan percibir de él. Aquellas mujeres y hombres nos enseñan hoy sus mundos y nosotros los aprehendemos. Sus miedos, sus deseos, sus talentos, sus manos, atraviesan decenas de miles de años, piedra pintada mediante. Luego, con el surgimiento de las grandes civilizaciones la pintura se trasladó de la piedra al muro estucado, con un mensaje algo menos abstracto y con fines y destinatarios más precisos, igualmente. Seguimos aprendiendo de ese arte y sus autores siguen comunicándonos sus ideas (o las de sus mecenas o tiranos), con la misma fuerza original. De hecho, algunos de esos dibujos/conceptos, en tanto simpleza y carácter práctico, pudieron ir abstrayéndose progresivamente hasta convertirse en letras, asomando la idea de un tejido de ideas; una textura; un texto.

Los primeros registros escritos se hacían sobre tablas de arcilla húmeda, lo que permitía el dejar la huella marcada. Muchas veces la información depositada en ellas era de un uso muy efímero, al punto que la arcilla volvía a alisarse para un nuevo uso, dando pie a la conocida expresión tábula rasa. Esas tablas eran usadas principalmente por escribas que registraban el movimiento de mercancías. Legaban cargamentos en caravanas o barcos, se contabilizaban los ingresos y egresos y allí finalizaba su utilidad. La arcilla se enrasaba y quedaba disponible, salvo que la información contenida fuera de importancia mayor, caso en el que se la dejaba secar y así solidificarse para consultas a futuro. La escritura es un maravilloso invento propio de los comerciantes. Hace alrededor de seis mil años el comercio requirió de su desarrollo como sistema de intercambio rápido de datos y de ese modo los fenicios legaron uno de los medios (no presenciales) de comunicación más importantes de la historia humana.

El acto de escribir fue migrando progresivamente hacia soportes menos durables. El papel, rey entre todos repositorios, tiene una vida útil bastante efímera, en términos históricos, sin embargo, ha sido el protagonista absoluto en la conservación de conceptos por más de cinco siglos, mucho más si a ello sumamos a sus antecesores, como el pergamino o el papiro.

En 1444 nace en Europa ${ }^{4}$ el libro impreso y resultó un producto más que novedoso. Su novedad fundamental radicaba en la supresión no solo del tiempo mediante entre autor y lector, como en los casos del arte rupestre, los muros pintados o la piedra grabada, sino que innovó radicalmente en la eliminación de la distancia geográfica existente entre quien dice y quien quiere aprehender de lo dicho. Probablemente la imprenta sea la primera línea de producción seriada de la historia y esa producción en serie del libro impreso resultó progresivamente en cantidades cada vez mayores de potenciales lectores. Difícil ponerse en la piel de un escritor del siglo $\mathrm{XVI}^{5}$ pero debe haber sido fascinante imaginar las potencialidades de ese nuevo producto cultural. Las posibilidades casi ilimitadas de alcance de sus obras escritas; la perdurabilidad de sus palabras, más allá de lo efímero del papel como soporte, ya que con la misma imprenta nace también la idea de la reimpresión de material, cuasi proto reedición de obras. El propio Gutenberg hizo más de una edición de La Biblia antes de morir ${ }^{6}$. Pero la producción seriada de códices no fue la única ma- 
nifestación cultural del Occidente humanista en conseguir conectar hasta a los propios continentes, y Cristóbal Colón en su vuelta a España no hizo otra cosa que enseñar a los Reyes Católicos las plantas, los animales y los habitantes humanos de lo que él creía eran las Indias, usándolos a modo de pantallas proyectivas de lo que fuese allende el mar. La imprenta entonces, no estuvo sola. Dice Ortega en su Meditación de la técnica que hay cuatro inventos contemporáneos para el mundo europeo gótico renacentista, que ponen al hombre al alcance de lo lejano. A saber: la pólvora, la brújula, el compás y la imprenta. En palabras del español: "el cañón pone en contacto inmediato a los enemigos lejanos" (a tiro, agregamos nosotros);” la brújula y el compás, al hombre con el astro y los puntos cardinales; la imprenta, al individuo solitario, ensimismado, con esa periferia infinita que es la humanidad de posibles lectores" (Ortega \& Gasset, 1982). Es esa infinita humanidad de potenciales interlocutores la que ya puso a los autores del pasado en situación similar a la que podríamos tener hoy frente a las pantallas. Nuestros alumnos hoy toman nota a partir de una exposición grabada por nosotros hace un año y nosotros mismos volvemos a escucharnos para refrescar un discurso que pertenece a un expositor que ya dejamos de ser. La misma extraña sensación que cuando releemos un escrito que pudimos publicar hace un tiempo. En la educación, tal y como la conocemos y practicamos desde siempre, la ausencia del autor es casi permanente. Salvo en una que otra conferencia magistral, en nuestros mal llamados teóricos, lo que hacemos en verdad es exponer teorías elaboradas por otra gente y al final de cuentas no somos otra cosa que un medio más de comunicación. Somos meros proveedores del saber que produjeron otros; meras vías de un discurso tercerizado. Y las mismas dudas que sufrimos hoy al dictar clases frente a los black mirrors, sin saber a ciencia cierta si hay interlocutores atentos del otro lado, son y fueron ampliamente superadas por aquellas del escritor, que escribe sin la certeza de si será o no leído alguna vez. Distinta es la calidad en el ensimismamiento del lector, que no busca quién lo escuche sino una voz que, resonando en su cabeza, se imbrique con sus propios pensamientos y, finalmente, lo ayude a educarse.

Y cómo habrá resonado la cabeza de las mujeres y hombres del bajo medioevo ante los vitrales de las catedrales góticas, fabuloso antecedente del dibujo animado. Animado en el sentido de la vida insuflada por el paso de la luz y su cambio de matices a través del transcurrir de las horas. Historias bíblicas enteras han sido transmitidas con todo éxito y por generaciones y ese éxito residía en gran medida en el hecho de estar dirigidas, en su momento, a un público masivamente analfabeto, que no podía acceder a otros medios de enseñanza más profunda como el libro. Enorme paralelo podríamos trazar entre la fascinación que en el ignorante hombre común del medioevo producían los vitrales y nuestra absorta mirada hoy sobre las coloridas pantallas.

La virtualidad de la comunicación ha crecido sin parar a caballo de una progresiva y constante desmaterialización de los repositorios de información, que prosigue hasta llegar a nuestra actual nube, sin olvidar al proceso previo descrito por la fotografía, las ondas de radio, la televisión, la Internet y la digitalización de todo lo posible de ser digitalizado, en discos flexibles, luego compactos, luego sólidos. La nube es lo que claramente responde a la primaria definición de entelequia, ya que obedece a una cosa que lleva en su esencia el principio de su acción y sus fines. La nube es información y lo es en acto, porque se re- 
construye permanentemente y su propósito es seguir haciéndolo. La popular y deformada definición de entelequia, refiere a la cosa que sólo existe en la imaginación y que es muy difícil de probar en su existencia ${ }^{7}$. Paradójicamente, para la mayoría de la humanidad la nube es igualmente una entelequia en ese vicioso sentido, porque se nos hace imposible imaginar a ese hipotético (para muchos) y gigantesco ordenador que guarda en su memoria el saber universal. En verdad no es uno, sino muchos y distribuidos por todo el mundo e interconectados entre sí. Ese inimaginable y gigantesco reservorio de datos se hace mucho más inasequible y virtual cuando entramos en conciencia de lo que podría ocurrir con todo eso frente a un potencial colapso energético. De hecho, en la intimidad de nuestras casas y trabajos y ante un simple corte de luz o caída de la señal de la internet, entramos literalmente en pánico.

Entonces; ¿Qué hay de nuevo en la educación no presencial? Creemos que muy poco, ya que la esencia de la educación es la no presencialidad, la intermediación, es decir, contar con medios que propicien ese acto entre educandos y educadores. Sólo son nuevos los soportes, sólo son nuevas las pantallas ${ }^{8}$.

En el aprendizaje y la enseñanza del diseño el concepto de pantalla o display no es nuevo; lo usamos desde siempre y muy vinculado al de interfase, que refiere a aquello que oficia de interconexión entre dos variables, sean éstas personales u objetuales. Es decir que para los diseñadores la mediación de pantallas en la comunicación, en este caso entre estudiantes y docentes (sin afirmar taxativamente quiénes están de un lado y quiénes del otro) no es un impedimento para el desarrollo de una clase. Pero nuestras clases poseen un perfil muy particular, fundamentalmente en las asignaturas proyectuales, y a esas clases las llamamos taller. Nuestro desafío hoy, en tiempos de virtualidad, es la reproducción más fiel posible de ese clima que es tan difícil de describir y que resulta del cúmulo de horas y horas de convivencia en horizontalidad creativa. Para ello es necesario transformarnos y de esa transformación resultarán seguramente nuevas maneras de educarnos, aunque el camino recién comienza y no se divisa horizonte, al menos por ahora.

\section{La virtualidad en el taller hoy}

El inicio del ciclo lectivo 2020, por demás particular, nos encontró en un torbellino de adaptaciones múltiples, tanto sea en el modo de trabajar como en el modo de habitar y convivir. Especialmente en los ámbitos educativos, entre esas múltiples adaptaciones los docentes debimos adecuar, modificar, sintetizar, seleccionar (y un sinfín de acciones más) el modo de trabajar los contenidos, de contactarnos con los estudiantes, de evaluar, entre otros.

Hasta pasados tres o cuatro meses del modo de clases no presencial, debido al Aislamiento Social Preventivo Obligatorio (ASPO), resultó muy difícil detenerse a pensar en cómo se estaba trabajando; cómo y con qué resultados. Fue más simple puestos en rol de estudiantes, justamente para capacitarnos - a contratiempo - en temáticas relacionadas con la enseñanza y el aprendizaje a distancia. Las dinámicas áulicas cotidianas se vieron atravesadas por kilómetros de separación entre los sujetos de ese espacio. La primera preocu- 
pación fue ¿Cómo acercarnos y salvar esa distancia? Nos sumergimos con los equipos de cátedra en la tarea de conocer, seleccionar y definir medios nuevos de comunicación. Sin embargo, en esa tarea estuvimos muy solos; fue como un andar a tientas, y seguramente con muchos errores.

Trabajamos en varias cátedras de la carrera de Diseño Industrial en la FAUD UNC, en los niveles I, III y IV; la misma urgencia por adaptarse a tientas y rápidamente hizo que las plataformas en coincidencia fueran escasas. Así fue como hubo que aprehender (tanto estudiantes como docentes) a movernos con mayor naturalidad que lo habitual en Zoom, Facebook, Gmail, Moodle, YouTube, Classroom, Slack y Drive. Como las herramientas y la comunicación no parecían ser suficientes y, hacer seguimiento de los procesos de los estudiantes y las correcciones correspondientes eran por demás difíciles, intentamos sumar aún más herramientas. En algunos casos se sumaron Padlet, Miró, Mentimeter y Meet. En otros se intentó intensificar la comunicación cotidiana a través de Instagram, pero nada parecía ser apropiado, suficiente o eficaz; nada reemplazaba el encuentro físico. Más allá de todo esto, resulta evidentemente claro que disponemos ahora de múltiples y novedosos recursos compatibles con lo que sucede en nuestro espacio áulico de taller, que inclusive potenciarían nuestro modo de trabajar, en el caso de una vuelta a lo presencial.

Sobre lo desordenado que resultó todo este proceso podemos fácilmente imaginar lo siguiente: si para nosotros, como docentes, la tarea de adaptarnos en cada clase-cátedra a diferentes plataformas fue ardua; ¿Cómo habrá sido para los estudiantes que cursan cinco, seis o siete materias simultáneamente? ¿Cómo se habrán sentido los ingresantes que sólo habitaron la facultad las tres semanas del Curso de Nivelación y de repente migraron a pantallas? Aún hoy, habiendo transcurrido más de un año de pandemia, seguimos aprendiendo, seguimos corrigiendo; es un desafío y revisión constante. La incertidumbre de este nuevo año en curso hace que estemos presentando nuestros planes A y previendo potenciales planes B, por cualquier emergente; seguramente es otro aprendizaje que nos dejará este ciclo. En fin, estas plataformas, en tanto elementos modelizantes en cuanto a la reconfiguración de la producción social de sentidos ${ }^{9}$, de algún modo nos han encontrado, a estudiantes y a docentes, aprehendiéndolas de modo conjunto. Entendemos a este contexto, desde una perspectiva pragmática, como una oportunidad; y que, de no tener lugar el ASPO, seguramente la inercia de la práctica cultural cotidiana no nos hubiese empujado a indagar, más no sea por curiosidad, este enorme, complejo y relativamente accesible universo de herramientas didácticas.

El espacio de taller habilita un aprender haciendo, que involucra a todos los sujetos que permanecen en él bajo una interacción cooperativa y constructiva, abordando situaciones problemáticas de modo interdisciplinario (Ander-Egg, 1999). El taller es así un espacio de convergencia y de síntesis que no aparenta presentar mayores dificultades para ser trabajado tanto de modo presencial como virtual. Esta estrategia metodológica y pedagógica se caracteriza por la participación activa de los estudiantes y el docente en un rol de facilitador o guía que acompaña a los estudiantes en sus procesos de aprendizaje operando mediante ajustes y correcciones variadas. Uno de los mayores desafíos de nuestro actual contexto en la enseñanza y el aprendizaje de las disciplinas proyectuales es la continuidad o permanencia del dispositivo didáctico de taller. Lo desafiante tiene que ver con sostener 
sus particularidades y las que nos son propias como colectivos y comunidad educativa. El taller es resultado de una imbricación de aspectos de diversa índole, entre ellos el modo de vinculación entre pares y entre docentes y estudiantes, el cierto aire de informalidad o cercanía que reina entre los diferentes claustros, las variadas y flexibles configuraciones del espacio áulico al servicio del acto pedagógico y las dinámicas de trabajo que ponemos en juego. Habitar un taller implica apropiación, acción, intercambio, construcción, reflexión, comunidad; es un estar presente y en ese sentido, existe una idea en el imaginario de la comunidad educativa de que la clase virtual será clase, en tanto y en cuanto tenga lugar la sincronicidad y la misma dure la totalidad de horas que duraba la clase presencial tal como la conocemos. Parece ser que en el proceso de adaptación de los contenidos y su puesta en práctica de lo que era la situación de presencialidad a la de conexión remota, nunca es suficiente. El taller como lo conocíamos hasta ahora tenía sus pantallas (paredes) donde compartíamos nuestros avances de proyectos, armábamos seminarios, críticas constructivas, correcciones colectivas, etc. Las pantallas del taller actual en cambio tienen múltiples pestañas, en reiteradas oportunidades es posible ver a algún estudiante escribir fluidamente o reírse en complicidad, y ahí sabemos que no está en el taller.

\section{Virtualidad y horizontalidad}

La educación no presencial ha sido, para la universidad pública y masiva, la realidad práctica del día a día desde hace décadas y muchas, por cierto. La educación superior pública, libre y gratuita, particularmente desde la segunda mitad del siglo pasado, es un baluarte irrenunciable que afortunadamente hemos sabido defender como sociedad, a pesar de los pesares históricos. Pero en esa masividad que esencialmente posee viene implícita la virtualidad; el alumno ignoto... Cátedras con matrículas de 800 estudiantes y un equipo docente de seis profesores hace muy difícil o imposible las relaciones interpersonales con fines educativos. El alumno ignoto es una hoja de papel en un parcial, una lámina en un trabajo práctico, una matrícula en nuestras listas, y no resulta exagerado afirmar que muchas y muchos transitan el año lectivo entero sin que crucemos con siquiera una mirada, muchísimo menos un diálogo. Sin embargo, los estudiantes cuentan hoy con un repertorio muchísimo mayor de vías de acceso al profesor en cuestión que aquellas que tuviéramos nosotros como alumnos. Nuestra única alternativa era la hora de clase, obviamente presencial. No había redes sociales, ni mensajería instantánea, siquiera teléfonos móviles. Había correo en papel, pero poco confiable y el tiempo de vida de una carta en sobre era correlativo al propio acto del reparto que hacía el pedestre cartero. Nuestro vínculo interpersonal con nuestras profesoras y profesores no fue nunca horizontal pero esa verticalidad hoy no ha sido erradicada por haber extrapolado la educación a las redes sociales; más bien ha sido refrescada. La distancia simbólica que sigue existiendo entre el profe (por más que nos llamen así) y los chicos (por más que los sigamos considerando de ese modo) resulta todavía infranqueable para muchos. Facebook, por poner como ejemplo a la más masiva de las redes, nos ha ofrecido una falsa sensación de proximidad, de vínculo, de 
conocimiento del otro y que no es más que una finísima y superficial cáscara que no difiere mucho de lo que elegimos mostrar al mundo cuando salimos a caminar por la calle. Sin necesidad de avanzar sobre territorios privados, tenemos las herramientas para cumplir con el desafío de horizontalizar aún más el complejo aprendizaje-enseñanza sin presentarnos frente a alumnos que desconocemos, como docentes para ellos desconocidos, mecánicos medios de repetición de saberes escritos por otra gente, muy lejos y hace mucho. En cuanto a nuestras disciplinas y el modo de trabajarlas, ¿será que estamos a la puerta de un nuevo taller?, ni horizontal, ni vertical, ni total...el taller virtual. Somos protagonistas de esta historia que está escribiéndose ahora, está en nosotros construir el futuro, potenciar el presente y dibujar juntos nuestro transformado espacio de estudio, enseñanza y aprendizaje.

\section{Notas:}

1. Hablamos del acto de reservar y no de guardar, porque implica la idea de un uso a futuro y no de la simple protección.

2. Nótese que tanto virtud como virtual, ambas palabras comparten la misma raíz latina: virtus.

3. Dice Ernst Gombrich: "Pero aunque estoy seguro de que siempre debemos tratar de enseñar menos y no más, esto no nos absuelve de nuestra responsabilidad de ayudar al alumno a hacer un buen uso del tiempo así ganado". En: Ideales e ídolos [1979] 1999, p. 20.

4. En Extremo Oriente la idea de imprenta existía desde cuatro siglos antes, por lo menos.

5. Convengamos en que la verdadera difusión del libro impreso comienza recién un siglo después de la invención de Gutenberg y su yerno en 1444 .

6. En esos primeros tiempos fue la Biblia la única obra que pasara por la imprenta.

7. Probablemente esa deformación devenga del hecho de que el propio Aristóteles fraguó ese concepto para definir al alma humana, pero no como aquello que existe en la imaginación y no puede probarse en su existencia, sino como lo que guarda en su esencia los principios de su propia acción y de sus fines

8. Paradójico es que la definición original de pantalla refiera a aquello que se interpone ante la luz directa para proteger a nuestros ojos.

9. Si bien este concepto es tomado de Novomisky, el autor lo trabaja en toda su obra, anclado al desarrollo elaborado originalmente por Jorge Huergo

\section{Listado de Referencia Bibliográfica}

Ander-Egg, E. (1999). El taller: una alternativa de renovación pedagógica. Buenos Aires: Magisterio del Río de la Plata.

Bourdieu, P., \& Passeron, J. (2014). Los herederos. Los estudiantes y la cultura. Buenos Aires: Siglo Veintiuno Editores. 
Gombrich, E. (1999). Ideales e ídolos. Madrid: Debate.

Novomisky, S. (2020). La marca de la convergencia: doce ensayos en busca de una narrativa. La Plata: Universidad Nacional de La Plata. Facultad de Periodismo y Comunicación Social. Otega \& Gasset, J. (1982). La meditación de la técnica. Madrid: Alianza.

\begin{abstract}
The impact of the pandemic on current education is transcendental at all levels, in higher education it is somehow salvageable and even sometimes allows those who could not have moved to study; With this in our disciplines, when reconstructing our idea of a workshop in this situation of digital mediation, it seems that we are losing and winning. Do we lose and win? Or we simply transform, mutate, hybridize and enhance. We have found the possibility of working together on a common canvas, of looking for information or corroborating questions instantly, of sharing transmedia resources and incorporating them into our libraries or backgrounds; We have also learned to value everyday life with our peers, the tangible.
\end{abstract}

Keywords: Virtuality - Workshop - Project disciplines - Teaching - Learning

Resumo: O impacto da pandemia na educação atual é transcendental em todos os níveis, no ensino superior é algo recuperável e às vezes permite que aqueles que não poderiam ter se mudado estudem; Com isso em nossas disciplinas, ao reconstruir nossa ideia de oficina nesta situação de mediação digital, parece que estamos perdendo e vencendo. Perdemos e ganhamos? Ou simplesmente transformamos, mudamos, hibridizamos e melhoramos. Encontramos a possibilidade de trabalhar juntos em uma tela comum, de buscar informações ou corroborar questões instantaneamente, de compartilhar recursos transmídia e incorporá-los em nossas bibliotecas ou fundos; Também aprendemos a valorizar a vida cotidiana com nossos colegas, o tangível.

Palavras chave: Virtualidade - Oficina - Disciplinas de projeto - Ensino - Aprendizagem [Las traducciones de los abstracts fueron supervisadas por el autor de cada artículo] 